\title{
PENGARUH SALURAN DISTRIBUSI DAN KUALITAS PELAYANAN TERHADAP KEPUTUSAN PEMBELIAN PRODUK ALAT KESEHATAN MEREK OMRON PADA PT. SUMBER MEDIKA INDONESIA MEDAN (DISTRIBUTOR ALAT KESEHATAN)
}

\author{
Oleh : \\ Felicia Wijaya ${ }^{1)}$, Andy $^{2)}$, Vincent ${ }^{3)}$, Steven ${ }^{4)}$, dan \\ Rahmat Alamsyah Harahap ${ }^{5)}$ \\ Universitas Prima Indonesia, Medan 1,2,3,4,5) \\ E-Mail : \\ feliciawi0905@gmail.com ${ }^{1)}$, andyrusli623@gmail.com 2), vincent.limz16@ gmail.com ${ }^{3)}$, \\ lim.steven25@gmail.com ${ }^{4)}$,rahmatalamsyah@yahoo.com ${ }^{5)}$
}

\begin{abstract}
This research aims at finding the effect of (1) distribution channels for purchasing decisions, (2) service quality for purchasing decisions, (3) distribution channels and service quality on purchasing decisions. The research method is a quantitative approach, a type of quantitative descriptive research in which it is explanatory research. Techniques of collecting data are by having interview, questionnaire and documentation study. Data analysis method is multiple linear regressions by testing the classical assumptions of normality, multicollinearity and heteroscedasticity. The population of this research is 232 customers, samples were taken by simple random sampling, as many as 147 customers and 30 customers were tested both validity and reliability. Research findings show that simultaneous distribution channels and service quality (Test $F$ ) have a positive effect on purchasing decisions with a value of 18,568. Partially (Test t) distribution channels have a positive and significant effect with a value of 2.802 and service quality has a positive and significant effect with a value of 2.963 on purchasing decisions. The test results of the coefficient of determination ( $R$ Square) obtained Adjusted R Square of 0.194 means that the distribution channels and service quality affect the purchasing decisions with a percentage level of $19.4 \%$ while the remaining $80.6 \%$ are other factors that were not examined by researcher.
\end{abstract}

Keywords: Distribution channels, Service quality and purchasing decisions

\section{PENDAHULUAN}

Dalam menghadapi persaingan bisnis yang begitu ketat, perusahaan dihadapkan diakibatkan karena banyaknya pelanggan pada resiko penurunan penjualan yang memutuskan membeli produk di perusahaan lain. Keputusan pembelian 
merupakan tindakan pelanggan dalam memutuskan membeli produk pada suatu perusahaan.

Keputusan pembelian merupakan keputusan yang dimiliki oleh seorang konsumen dalam melakukan sebuah pembelian. Dalam menentukan pembelian, semua hal yang berkaitan dengan pembelian, pembeli selalu menentukan berbagai hal yang mereka anggap penting. Beberapa hal yang dapat mempengaruhi keputusan pembelian salah satu diantaranya adalah saluran distribusi.

Saluran distribusi merupakan saluran pemasaran yang dimiliki oleh perusahaan dalam menyalurkan semua produk yang dimiliki oleh perusahaan. Perusahaan menyediakan distribusi yang baik untuk mendukung penjualan dan pengantaran produk-produk yang dibeli kepada pelanggan sebagai bentuk servis kepada pelanggan. Saluran distribusi yang baik perlu ada untuk membuat kenyamanan bagi pelanggan.

Kualitas pelayanan merupakan kualitas yang dimiliki oleh perusahaan dalam menyediakan pelayanan setelah pelanggan melakukan pembelian. Penilaian pelayanan ini menjadi unsur utama bagi pelanggan dalam menilai kriteria perusahaan.

PT. Sumber Medika Indonesia Medan adalah salah satu perusahaan yang bergerak di bidang distribusi alat-alat kesehatan bermerek DR Care, Breastlight, Beurer dan merek lainnya. Produk-produk yang dipasarkan beberapa diantaranya alat kesehatan seperti : jarum suntik, oksigen, obat-obatan, busa, alat penjahit kulit, stetoskop dan lainnya. Perusahaan ini beralamat di Jalan Kompleks Multatuli Blok B No 51-52 Medan.

Dari hasil wawancara dan pengamatan penelitian di dapatkan permasalahan yang muncul dalam perusahaan pada keputusan pembelian menunjukkan bahwa pencapaian target dari perusahaan tidak mencapai target setiap bulannya sesuai dengan yang telah ditetapkan perusahaan, Penurunan ini terjadi dikarenakan adanya perusahaan lain yang menawarkan produk dengan harga yang lebih murah dari perusahaan sehingga terjadinya penurunan penjualan, keputusan konsumen atas pilihan jenis dan merek produk yang banyak dari beberapa perusahaan sejenis yang mereka inginkan, cara penjualan dan waktu pembelian konsumen yang dijalankan oleh perusahaan.

Dari hasil wawancara dan pengamatan penelitian di dapatkan permasalahan yang muncul dalam perusahaan pada saluran distribusi dapat terlihat bahwa sering terjadi keterlambatan distribusi di perusahaan dalam hal waktu tunggu dan waktu pengiriman barang, kurangnya pelayanan spesial yang 
diberikan kepada pelanggan pareto (utama), dan keragaman produk dari perusahaan yang terlalu banyak.

Dari hasil wawancara dan pengamatan penelitian di dapatkan permasalahan yang muncul dalam perusahaan pada kualitas pelayanan menunjukkan bahwa sering terjadi komplain oleh pelanggan setiap bulan dikarenakan karyawan kurang handal, kurang sigap dan cepat dalam memberikan pelayanan dan kurangnya kepastian pelayanan yang diberikan perusahaan kepada pelanggan.

Berdasarkan fenomena permasalahan yang ditemukan, peneliti melakukan penelitian dengan judul "Pengaruh Saluran Distribusi dan Kualitas Pelayanan Terhadap Keputusan Pembelian Produk Alat Kesehatan Merek Omron Pada PT. Sumber Medika Indonesia Medan (Distributor Alat Kesehatan)".

\section{Identifikasi Masalah}

1. Saluran distribusi yang masih menjadi masalah dikarenakan keterlambatan pengantaran barang sampai ke pelanggan.

2. Kualitas pelayanan yang belum maksimal dikarenakan munculnya komplain dari pelanggan yang merasa tidak puas dengan pelayanan yang diberikan.
3. Keputusan pembelian pelanggan yang menurun dilihat dari perusahaan tidak mampu mencapai target penjualan setiap bulannya.

\section{Perumusan Masalah}

1. Bagaimana pengaruh saluran distribusi terhadap keputusan pembelian produk alat kesehatan merek Omron pada PT. Sumber Medika Indonesia Medan?

2. Bagaimana pengaruh kualitas pelayanan terhadap keputusan pembelian produk alat kesehatan merek Omron pada PT. Sumber Medika Indonesia Medan?

3. Bagaimana pengaruh saluran distribusi dan kualitas pelayanan terhadap keputusan pembelian produk alat kesehatan merek Omron pada PT. Sumber Medika Indonesia Medan ?

\section{Tujuan Penelitian}

1. Untuk menguji dan menganalisis pengaruh saluran distribusi terhadap keputusan pembelian produk alat kesehatan merek Omron pada PT. Sumber Medika Indonesia Medan.

2. Untuk menguji dan menganalisis pengaruh kualitas pelayanan terhadap keputusan pembelian produk alat kesehatan merek Omron pada PT. Sumber Medika Indonesia Medan.

3. Untuk menguji dan menganalisis pengaruh saluran distribusi dan kualitas pelayanan terhadap keputusan 
pembelian produk alat kesehatan merek Omron pada PT. Sumber Medika Indonesia Medan.

\section{Manfaat Penelitian}

1. Bagi peneliti

Sebagai bahan pengetahuan untuk memperluas wawasan peneliti dalam bidang ilmu manajemen pemasaran.

2. Bagi Program Studi S1 Manajemen Fakultas Ekonomi Universitas Prima Indonesia

Hasil penelitian ini diharapkan dapat menjadi bahan studi kepustakaan, pembelajaran dan memperkaya penelitian ilmiah di Universitas Prima Indonesia, khususnya Program Studi S-1 Manajemen Fakultas Ekonomi.

3. Bagi Perusahaan PT. Sumber Medika Indonesia Medan.

Hasil penelitian ini diharapkan dapat memberikan bahan pertimbangan berkaitan dengan saluran distribusi dan kualitas pelayanan untuk meningkatkan keputusan pembelian pada PT. Sumber Medika Indonesia Medan.

4. Bagi peneliti selanjutnya

Hasil penelitian ini diharapkan dapat menjadi tambahan rujukan, bahan referensi bagi peneliti selanjutnya dan informasi bagi pihak yang berkepentingan untuk mengkaji masalah yang sama di masa mendatang.

\section{METODE PELAKSANAAN}

\section{Teori tentang saluran distribusi}

Menurut Tjiptono (2015:347), saluran distribusi (marketing channel, trade channel, distribution channel) adalah rute atau rangkaian perantara, baik yang dikelola pemasar maupun yang independen dalam menyampaikan barang dari produsen ke konsumen.

Menurut Laksana (2008:123), saluran pemasaran atau saluran distribusi adalah serangkaian organisasi yang terkait dalam semua kegiatan yang digunakan untuk menyalurkan produk dan status pemilikannya dari produsen ke konsumen.

Menurut Abdullah dan Tantri (2012:207), saluran pemasaran dapat dilihat sebagai sekumpulan organisasi yang saling tergantung satu sama lainnya yang terlihat dalam proses penyediaan sebuah produk atau pelayanan untuk digunakan atau dikonsumsi.

\section{Teori tentang kualitas pelayanan}

Menurut Laksana (2008:88), kualitas pelayanan adalah tingkat mutu yang diharapkan, dan pengendalian keragaman dalam mencapai mutu tersebut untuk memenuhi kebutuhan konsumen.

Menurut Schiffman dan Kanuk (2007:164), kualitas pelayanan merupakan fungsi dari besar dan arah kesenjangan antara harapan pelanggan mengenai jasa 
dan penilaian (persepsi) pelanggan mengenai jasa yang diberikan.

Menurut Tjiptono (2012:3), service mengisyaratkan segala sesuatu yang dilakukan pihak tertentu (individu maupun kelompok) kepada pihak lain (individu maupun kelompok). Salah satu contohnya adalah layanan pelanggan (customer service).

\section{Teori tentang keputusan pembelian}

Menurut Sangadji dan Sopiah (2013:37), "Keputusan pembelian merupakan tahap dalam proses pengambilan keputusan pembelian sampai konsumen benar-benar membeli produk."

Menurut Tjptono (2015:184), "Keputusan pembelian adalah perilaku yang ditunjukkan oleh konsumen dalam mencari, membeli, menggunakan, mengevaluasi, dan menghentikan konsumsi produk dan jasa yang mereka harapkan dapat memuaskan kebutuhan mereka."

Menurut Nitisusastro (2013:195), "Menegaskan bahwa pengambilan keputusan konsumen merupakan proses interaksi antara sikap afektif, sikap kognitif, sikap behavioral dengan faktor lingkungan dengan mana manusia melakukan pertukaran dalam semua aspek kehidupannya".

\section{Teori pengaruh saluran distribusi} terhadap keputusan pembelian
Menurut Adisaputro (2014:233), agar produk dapat diakses oleh calon pembeli maka terhadap produk perlu dilakukan kegiatan distribusi dan penjualan ke berbagai titik-titik penjualan (point of purchases) yaitu berupa penjualan langsung pada konsumen ataupun lewat sistem perantara pemasaran misalnya dalam bentuk distributor, pedagang besar, dan pedagang pengecer yang akan langsung berhadapan dengan calon konsumen. Kegiatan untuk meningkatkan akses produk pada calon pembeli inilah yang dimaksudkan dengan value delivery.

Menurut Nitisusastro (2013:201), implikasi saluran distribusi terhadap perilaku konsumen bagi konsumen kondisi yang paling ideal adalah ketika memerlukan sesuatu produk, maka informasi tentang produk yang dibutuhkan bisa diperoleh dengan mudah, murah dan menyenangkan.

Menurut Hasan (2013:173), "Dapat dikatakan bahwa minat beli merupakan pernyataan mental dari konsumen yang merefleksikan rencana pembelian sejumlah produk dengan merek tertentu. Minat beli masa mendatang sangat dipengaruhi oleh pengalaman pelanggan yang berkaitan dengan harga, merek, promosi, iklan, rantai pasokan, kombinasi (mix) layanan, suasana, dan lokasi (tempat)." 


\section{Teori pengaruh kualitas pelayanan terhadap keputusan pembelian}

Menurut Schiffman dan Kanuk (2007 : 166), jika penilaian terhadap kualitas pelayanan tinggi, maksud perilaku pelanggan akan menguntungkan perusahaan dan mereka mungkin akan tetap menjadi pelanggan. Jika penilaian terhadap pelayanan rendah, hubungan ke pelanggan lebih mungkin melemah, yang mengakibatkan penyebrangan ke pesaing.

Menurut Manap (2016:383), sebuah perusahaan jasa harus menjaga kualitas jasa yang ditawarkan harus berada di atas saingan dan lebih hebat dari yang dibayangkan oleh konsumen. Apabila kualitas jasa yang diterima oleh konsumen lebih baik atau sama dengan yang ia bayangkan, maka ia cenderung akan mencobanya kembali.

Menurut Haryono (2016:42), karena adanya layanan pelanggan yang prima, pelanggan akan semakin mempercayai perusahaan. Dengan memberikan keahlian atau keadalannya untuk memuaskan pelanggan, secara tidak langsung perusahaan membangun hubungan yang intens dengan pelanggan. Pelanggan yang merasa tepat memilih perusahaan untuk melakukan pembelian ulang.

\section{Kerangka Konseptual dan Hipotesis}

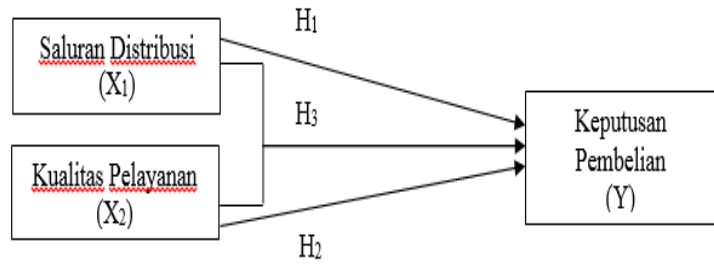

Gambar Kerangka Konseptual

Hipotesis dalam penelitian ini adalah:

$\mathrm{H}_{1}$ : Saluran distribusi berpengaruh terhadap keputusan pembelian produk alat kesehatan merek Omron pada PT. Sumber Medika Indonesia Medan.

$\mathrm{H}_{2}$ : Kualitas pelayanan berpengaruh terhadap keputusan pembelian produk alat kesehatan merek Omron pada PT. Sumber Medika Indonesia Medan.

$\mathrm{H}_{3}$ : Saluran distribusi dan kualitas pelayanan berpengaruh terhadap keputusan pembelian produk alat kesehatan merek Omron pada PT. Sumber Medika Indonesia Medan.

\section{HASIL DAN PEMBAHASAN}

\section{Tempat dan Waktu Penelitian}

Penelitian ini akan dilakukan di PT. Sumber Medika Indonesia Medan yang berlokasi di Jalan Kompleks Multatuli Blok B No 51-52 Medan.

\section{Pendekatan Penelitian}

Pendekatan penelitian ini berdasarkan pendekatan kuantitatif karena penelitian ini memiliki alur yang jelas dan teratur. Pendekatan kuantitatif dapat diartikan sebagai metode penelitian yang 
berlandaskan pada filsafat positivisme, digunakan untuk meneliti pada populasi atau sampel tertentu, pengumpulan data menggunakan instrument penelitian, analisis data bersifat kuantitatif/statistik, dengan tujuan untuk menguji hipotesis yang telah ditetapkan.

\section{Jenis Penelitian}

Jenis penelitian ini merupakan jenis penelitian deskriptif. Menurut Arikunto (2010:3), "Penelitian deskriptif adalah penelitian yang dimaksudkan untuk menyelidiki keadaan, kondisi atau hal-hal lain yang sudah disebutkan, yang hasilnya dipaparkan dalam bentuk laporan penelitian".

\section{Sifat Penelitian}

Sifat penelitian ini adalah deskriptif exsplanatory.

\section{Populasi dan Sampel Penelitian}

Populasi

Populasi dalam penelitian ini adalah pelanggan tetap yang melakukan pembelian rutin di PT Sumber Medika Indonesia Medan dari bulan Januari Desember 2017 sebanyak 232 pelanggan.

\section{Sampel}

Teknik pengambilan sampel menggunakan teknik simple random sampling dengan rumus Slovin. Sampel penelitian ini adalah sebanyak 147 sampel, dimana 30 outlet diambil dari luar sampel sebagai sampel uji validitas dan realibilitas, sedangkan 147 outlet diambil untuk pengujian sampel penelitian.

\section{Teknik Pengumpulan Data}

Teknik pengumpulan data yang digunakan adalah

1. Wawancara

2. Kuesioner

3. Studi dokumentasi

\section{Jenis dan Sumber Data}

1. Sumber data primer

Dengan melakukan tanya jawab secara langsung dengan konsumen PT Sumber Medika Indonesia Medan.

2. Sumber data sekunder

Dengan membuat daftar pertanyaan dalam bentuk kuesioner yang ditujukan kepada konsumen tetap PT Sumber Medika Indonesia Medan.

\section{Operasional Variabel Penelitian}

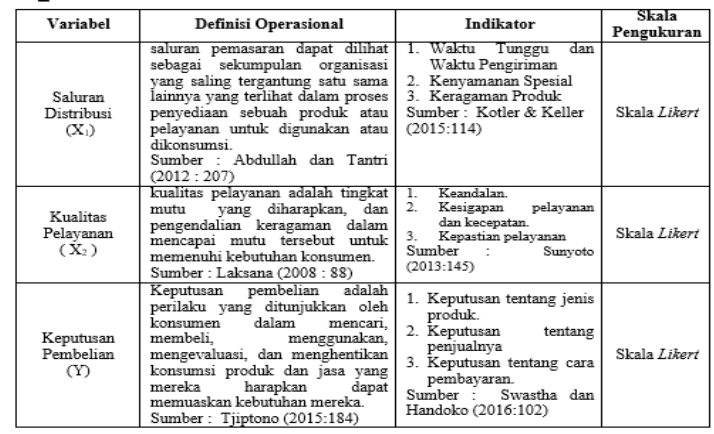

Statistik Deskriptif

\begin{tabular}{|c|c|c|c|c|c|c|}
\hline \multicolumn{7}{|c|}{ Descriptive Statistics } \\
\hline & $N$ & llinimum & Haximu & & Ilean & $\begin{array}{c}\text { Sito. } \\
\text { Deviation }\end{array}$ \\
\hline SALLPANDSTRBDUS| & & & 6 & 9 & 21 & $8 \quad 4,00$ \\
\hline KUALITSSPELAYANAN & & 17] & 9 & 9 & 20 & $\begin{array}{ll}4 & 487\end{array}$ \\
\hline KEPVTUSANPEEIBELLAN & & 17] & 15 & 7 & 21 & \begin{tabular}{l|l}
$3 \quad 241$ \\
3
\end{tabular} \\
\hline VardN/(ishise) & & 17] & & & & \\
\hline
\end{tabular}


Dari hasil data statistik deskriptif diperoleh pada indikator variabel saluran distribusi dengan sampel 147 orang responden memiliki rata-rata sebesar 21,28 satuan dengan nilai minimum 6 satuan pada responden nomor 147 dan nilai maksimum 29 satuan pada responden nomor 86 dengan standard deviasi 4,006.

Indikator variabel kualitas pelayanan memiliki rata-rata sebesar 20,74 satuan dengan nilai minimum 9 satuan pada responden nomor 132, 135, 136 dan 147 dan nilai maksimum 29 satuan pada responden nomor 26 dengan standard deviasi 4,875.

Indikator variabel keputusan pembelian memiliki rata-rata sebesar 21,33 satuan dengan komposisi nilai minimum 15 satuan pada responden nomor 6 dan nilai maksimum 73 satuan pada responden nomor 81 dengan standard deviasi 2,417.

\section{Hasil Uji Asumsi Klasik}

\section{A. Uji Normalitas}

1. Uji menggunakan grafik

\section{a. Grafik Histogram}

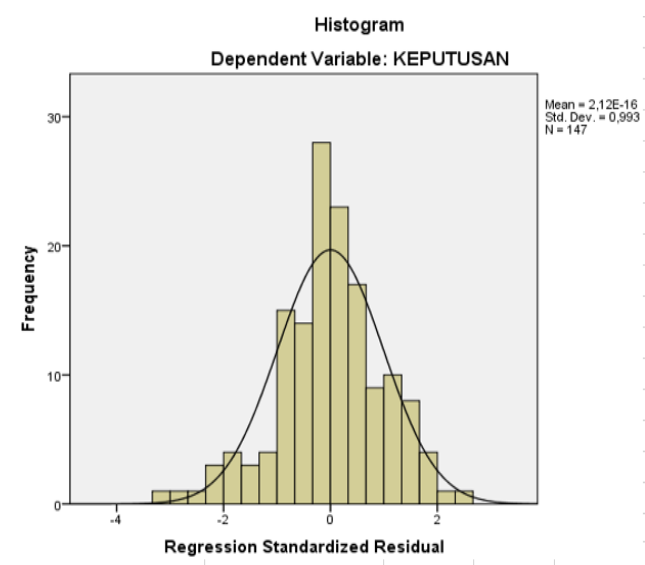

Dari grafik histogram didapat pola garis berbentuk lonceng tidak melenceng ke kiri atau pun ke kanan maka data berdistribusi normal.

b. Grafik Probability Plot

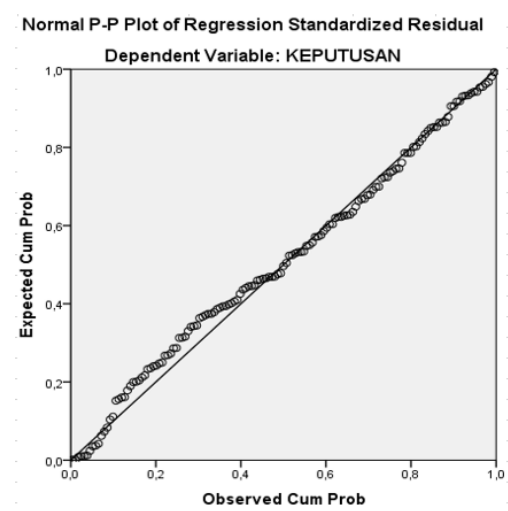

Dari grafik Probability Plot didapat pola garis berbentuk menyebar disekitar garis diagonal, penyebarannya sebagian besar mendekati garis diagonal maka data berdistribusi normal.

2. Uji menggunakan Kolmogorov-Smirnov

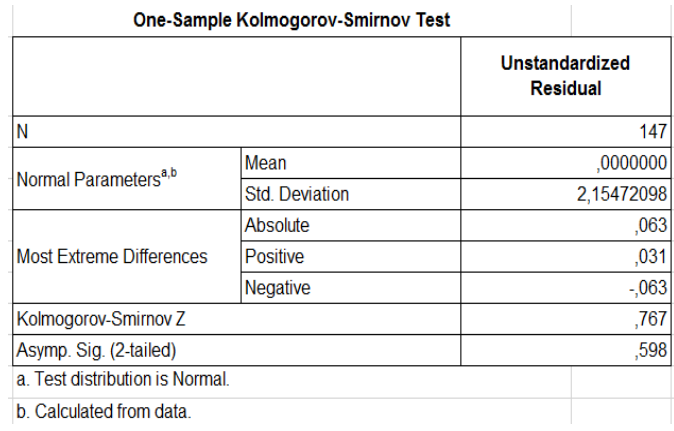

Dari hasil uji dengan metode Kolmogorov Smirnov didapat nilai signifikan $0,598>0,05$ dengan demikian hasil data menunjukkan terdistribusi normal.

\section{B. Uji Multikolinearitas}




\begin{tabular}{|c|c|c|c|}
\hline \multicolumn{4}{|c|}{ Coefficients $^{a}$} \\
\hline \multirow{2}{*}{ Model } & & \multicolumn{2}{|c|}{ Collinearity Statistics } \\
\hline & & Tolerance & $V \mid F$ \\
\hline \multirow{2}{*}{1} & SALURAN DISTRIBUS| & .695 & 1,439 \\
\hline & KUALITAS PELAYANAN &, 695 & 1,439 \\
\hline
\end{tabular}

Nilai tolerance untuk variabel saluran distribusi dan kualitas pelayanan sebesar 0,695 berada diatas 0,10 dan nilai variance inflation factor (VIF) variabel saluran distribusi dan kualitas pelayanan 1,439 berada dibawah 10 , maka pada uji multikolinearitas tidak terjadi multikolinieritas antar variabel bebas dalam model regresi.

\section{Uji Heteroskedastisitas}

\section{Uji Grafik Scatterplot}

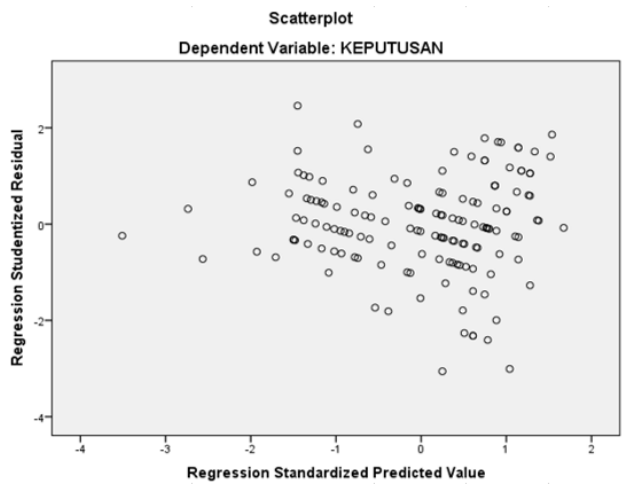

Dari hasil data yang diperoleh pada grafik Scatterplot tidak ada pola yang jelas, serta titik-titik menyebar di atas dan di bawah angka 0 pada sumbu $Y$, maka tidak terjadi heteroskedastisitas

2. Uji statistik metode Glejser

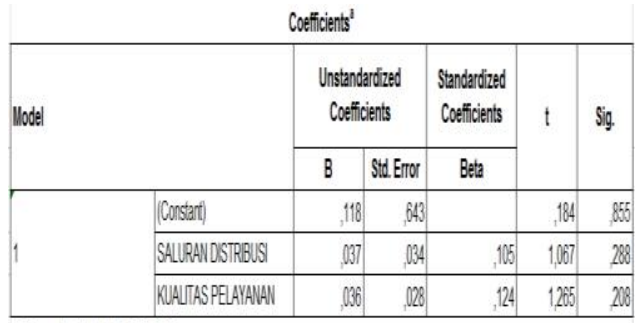

a Dependert Varable: ABS RES

Diperoleh probabilitas signifikan (Sig.) saluran distribusi $0,288(0,288$ $>0,05)$ dan kualitas pelayanan 0,208 $(0,208>0,05)$ di atas tingkat kepercayaan 5\%, maka dapat disimpulkan model regresi tidak terjadi heteroskedastisitas.

Hasil Analisis Data Penelitian

\begin{tabular}{|c|c|c|c|c|}
\hline \multicolumn{5}{|c|}{ Coefficientsa } \\
\hline \multirow[t]{2}{*}{ Model } & & \multicolumn{2}{|c|}{$\begin{array}{l}\text { Unstandardized } \\
\text { Coefficients }\end{array}$} & \multirow{2}{*}{$\begin{array}{c}\begin{array}{c}\text { Standardized } \\
\text { Coefficients }\end{array} \\
\text { Beta }\end{array}$} \\
\hline & & $B$ & Std. Error & \\
\hline \multirow{3}{*}{1} & (Constant) & 15,412 & 1,011 & \\
\hline & SALURAN DISTRIBUS| & 151 & 054 & 250 \\
\hline & KUALITAS PELAYANAN & 131 & 044 & 264 \\
\hline
\end{tabular}

Keputusan pembelian $=$

$15,412+0,151$ saluran distribusi $+0,131$

kualitas pelayanan.

Dapat dijelaskan bahwa :

1. Konstanta sebesar 15,412 menyatakan, jika saluran distribusi dan kualitas pelayanan tidak ada atau konstan maka keputusan pembelian sebesar 15,412 satuan.

2. Koefisien regresi saluran distribusi sebesar 0,151 dan bernilai positif, hal ini menyatakan bahwa setiap kenaikan saluran distribusi 1 satuan akan meningkatkan keputusan pembelian 
sebesar 0,151 satuan dengan anggapan variabel lainnya tetap.

3. Koefisien regresi kualitas pelayanan sebesar 0,131 dan bernilai positif, hal ini menyatakan bahwa setiap kenaikan kualitas pelayanan 1 satuan akan meningkatkan keputusan pembelian sebesar 0,131 satuan dengan anggapan variabel lainnya tetap.

\section{Uji Koefisien Determinasi}

\begin{tabular}{|c|c|c|c|c|}
\hline \multicolumn{5}{|c|}{ Model Summary ${ }^{b}$} \\
\hline Model & $R$ & RSquare & \begin{tabular}{|c|} 
Adjusted R \\
Square
\end{tabular} & $\begin{array}{c}\text { Sid. Error of the } \\
\text { Estimate }\end{array}$ \\
\hline 1 & $.453^{8}$ & 205 & 194 & 2,170 \\
\hline
\end{tabular}

a. Predictors: (Constant), KUALLTAS PELAYANAN, SALURAN DISTRRBUSI

b. Dependent Variable: KEPUTUSAN PEMBELLAN

Dari hasil uji koefisien determinasi didapat nilai Adjusted $R$ square (Adj R) sebesar 0,194 hal ini berarti $19,4 \%$ dari variasi variabel dependen keputusan pembelian dapat dijelaskan oleh variasi variabel independen saluran distribusi dan kualitas pelayanan sedangkan sisanya sebesar $80,6 \%(100 \%-19,4 \%)$ dapat dijelaskan oleh variabel lain yang tidak diteliti oleh peneliti pada penelitian ini.

\section{Pengujian Hipotesis}

1. Uji secara simultan (Uji F)

\begin{tabular}{|c|c|c|c|c|c|c|}
\hline \multicolumn{7}{|c|}{ ANOONA $^{8}$} \\
\hline \multicolumn{2}{|l|}{ Model } & $\begin{array}{l}\text { Sum of } \\
\text { Souzres }\end{array}$ & $d f$ & Mlean Square & $F$ & Sig. \\
\hline \multirow{3}{*}{1} & Regession & 174,815 & 2 & 87,407 & 18,568 & $.000^{b}$ \\
\hline & Residial & 677,852 & 144 & 4,707 & & \\
\hline & Total & 852667 & 146 & & & \\
\hline
\end{tabular}

a. Dependert Varade: KEPUTISAM PEMGELLAN

b. Predictos: (Constant), KUALITAS PELAYANAN, SALLRAN DITTRBUS|

Hasil uji signifikansi simultan (Uji F) didapat nilai $\mathrm{F}$ hitung sebesar 18,568 dari hasil perhitungan SPSS diperoleh nilai $\mathrm{F}_{\text {hitung }}>\mathrm{F}_{\text {tabel }}(18,568>3,06)$ dengan tingkat signifikansi 0,000 . Karena $\mathrm{F}_{\text {hitung }}>\mathrm{F}_{\text {tabel }}(18,568>3,06)$ dan probabilitas signifikansi $0,000<0,05$. Dapat disimpulkan $\mathrm{H}_{1}$ diterima artinya saluran distribusi dan kualitas pelayanan secara simultan berpengaruh positif dan signifikan terhadap keputusan pembelian.

2, Pengujian secara parsial $(\mathrm{Uji}-\mathrm{t})$

\begin{tabular}{|c|c|c|c|c|c|c|}
\hline \multirow[t]{2}{*}{ Illodel } & & \multicolumn{2}{|c|}{$\begin{array}{l}\text { Unstindarorized } \\
\text { Coefficients }\end{array}$} & \multirow{2}{*}{ 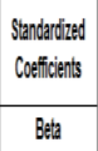 } & \multirow[t]{2}{*}{$t$} & \multirow[t]{2}{*}{ Sig. } \\
\hline & & $B$ & Stro. Error & & & \\
\hline \multirow{3}{*}{1} & (Consart) & 15,412 & 1,011 & & 15243 & 000 \\
\hline & SALURANDSTRPBUS| &, 151 &, 054 & 250 & 2802 & .000 \\
\hline & KUALTASPELLYANAN &, 131 &, 044 & 264 & 2963 & .04 \\
\hline
\end{tabular}

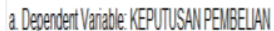

Dari hasil uji parsial (Uji t) didapat kesimpulan :

1. Secara parsial diperoleh nilai $t_{\text {hitung }}$ saluran distribusi 2,802 dengan nilai signifikan sebesar 0,006. Nilai $t_{\text {hitung }}>$ $\mathrm{t}_{\text {tabel }}(2,802>1,655)$ maka $\mathrm{H}_{1}$ diterima (tolak $\mathrm{H}_{0}$ ), artinya saluran distribusi berpengaruh positif dan signifikan terhadap keputusan pembelian produk alat kesehatan merek Omron pada PT. Sumber Medika Indonesia Medan (Distributor Alat Kesehatan).

2. Secara parsial diperoleh nilai $t_{\text {hitung }}$ kualitas pelayanan 2,963 dengan nilai signifikan sebesar 0,004 . Nilai $t_{\text {hitung }}>$ $\mathrm{t}_{\text {tabel }}(2,963>1,655)$ maka $\mathrm{H}_{1}$ diterima (tolak $\mathrm{H}_{0}$ ), artinya kualitas pelayanan berpengaruh positif dan tidak signifikan 
terhadap keputusan pembelian produk alat kesehatan merek Omron pada PT. Sumber Medika Indonesia Medan (Distributor Alat Kesehatan).

\section{Pembahasan Hasil Penelitian}

\section{Pengaruh saluran distribusi terhadap keputusan pembelian}

Dari hasil analisis pada uji secara parsial didapatkan bahwa pada indikator variabel saluran distribusi nilai $t_{\text {hitung }}>t_{\text {tabel }}$ $(2,802>1,655)$ dengan nilai signifikan $0,006<0,05$. Sehingga hipotesis $H_{1}$ diterima (tolak $\mathrm{H}_{0}$ ) karena $t_{\text {hitung }}>t_{\text {tabel }}$ $(2,802>1,655)$. Sehingga hasil penelitian dapat disimpulkan bahwa saluran distribusi berpengaruh positif dan signifikan terhadap keputusan pembelian dapat diterima. Hal ini sesuai dengan hipotesis peneliti diawal penelitian.

Hal ini didukung juga berdasarkan hasil penelitian terdahulu oleh peneliti Hariadi (2013) yang berjudul "Pengaruh Produk, Harga, Promosi dan Distribusi Terhadap Keputusan pembelian Konsumen pada Produk Projector Microvision“. Hasil penelitiannya menunjukkan secara simultan produk, harga, promosi dan distribusi berpengaruh signifikan terhadap keputusan pembelian projector microvision pada PT. Smart Vision Surabaya. Hasil secara parsial produk, harga, promosi dan distribusi berpengaruh signifikan terhadap keputusan pembelian projector microvision pada PT. Smart Vision Surabaya.

Hasil penelitian ini sependapat dengan teori Nitisusastro (2013:201), implikasi saluran distribusi terhadap perilaku konsumen bagi konsumen kondisi yang paling ideal adalah ketika memerlukan sesuatu produk, maka informasi tentang produk yang dibutuhkan bisa diperoleh dengan mudah, murah dan menyenangkan.

Dapat disimpulkan dari kuesioner atas 6 pertanyaan yang diberikan kepada responden didapat rata-rata mayoritas responden menjawab saluran distribusi sangat berpengaruh terhadap keputusan pembelian. Saluran distribusi perlu dijaga secara berkesinambungan agar pelanggan tetap mendapatkan barang pesanan sesuai dengan yang diharapkan dimanapun keberadaannya. Peneliti menyarankan kepada manajemen perusahaan harus selalu melakukan control dan mengevaluasi perangkat-perangkat apa saja yang mendukung atas keberhasilan dalam menjaga saluran distribusi perusahaan ke pelanggan.

\section{Pengaruh kualitas pelayanan terhadap keputusan pembelian}

Dari hasil analisis pada uji secara parsial didapatkan bahwa pada indikator variabel kualitas pelayanan nilai $t_{\text {hitung }}>$ $t_{\text {tabel }}(2,963>1,655)$ dengan nilai 
signifikan $0,004<0,05 . \quad$ Sehingga hipotesis $\mathrm{H}_{1}$ diterima (tolak $\mathrm{H}_{0}$ ) karena $t_{\text {hitung }}>t_{\text {tabel }}(2,963>1,655)$. Sehingga hasil penelitian dapat disimpulkan bahwa kualitas pelayanan berpengaruh positif dan signifikan terhadap keputusan pembelian dapat diterima. Hal ini sesuai dengan hipotesis peneliti diawal penelitian.

Hal ini didukung juga berdasarkan hasil penelitian terdahulu oleh peneliti Muhtadi dan Surahman (2015), yang berjudul "Pengaruh Kualitas Pelayanan dan Kepuasan Pelanggan terhadap Niat Beli Obat di Depo Farmasi Anggrek RSUP Dr. Hasan Sadikin Bandung“. Hasil penelitiannya menunjukkan secara simultan kualitas pelayanan, kepuasan pelanggan berpengaruh signifikan terhadap niat beli. Hasil secara parsial kualitas pelayanan, kepuasan pelanggan berpengaruh signifikan terhadap niat beli.

Hasil penelitian ini sependapat dengan teori Schiffman dan Kanuk (2007: 166), jika penilaian terhadap kualitas pelayanan tinggi, maksud perilaku pelanggan akan menguntungkan perusahaan dan mereka mungkin akan tetap menjadi pelanggan. Jika penilaian terhadap pelayanan rendah, hubungan ke pelanggan lebih mungkin melemah, yang mengakibatkan penyebrangan ke pesaing.

Dapat disimpulkan dari kuesioner atas 6 pertanyaan yang diberikan kepada responden didapat rata-rata mayoritas responden menjawab kualitas pelayanan sangat berpengaruh terhadap keputusan pembelian. Kualitas pelayanan perlu dijaga secara berkesinambungan agar pelanggan tetap merasa puas atas barang yang telah dipesannya. Kualitas pelayanan yang baik sebelum dan sesudah pelanggan membeli produk perusahaan akan berdampak terhadap pelanggan untuk menentukan keputusan pembeliannya dengan cepat dan mudah. Peneliti menyarankan kepada manajemen perusahaan agar selalu melakukan control dan mengevaluasi perangkat-perangkat apa saja yang mendukung atas keberhasilan dalam memelihara kualitas pelayanan perusahaan ke pelanggan.

\section{KESIMPULAN DAN SARAN}

\section{Kesimpulan}

1. Indikator variabel saluran distribusi secara parsial berpengaruh positif dan signifikan terhadap keputusan pembelian dapat diterima dengan nilai nilai $t_{\text {hitung }}>t_{\text {tabel }}(2,802>1,655)$ dengan nilai signifikan $0,006<0,05$. Hipotesis $\mathrm{H}_{1}$ diterima (tolak $\mathrm{H}_{0}$ ) karena $\mathrm{t}_{\text {hitung }} 2,802>\mathrm{t}_{\text {tabel }} 1,655$ (hipotesis diterima).

2. Indikator variabel kualitas pelayanan secara parsial berpengaruh positif dan signifikan terhadap keputusan pembelian dapat diterima dengan nilai nilai $t_{\text {hitung }}>t_{\text {tabel }}(2,963>1,655)$ dengan nilai signifikan $0,004<0,05$. 
Hipotesis $\mathrm{H}_{1}$ diterima (tolak $\mathrm{H}_{0}$ ) karena $t_{\text {hitung }} 2,963>t_{\text {tabel }} 1,655$ (hipotesis diterima).

3. Indikator variabel saluran distribusi dan kualitas pelayanan secara simultan berpengaruh positif dan signifikan terhadap keputusan pembelian dengan nilai $\mathrm{F}_{\text {hitung }}>\mathrm{F}_{\text {tabel }}(18,568>3,06)$ dengan signifikansi $0,000<0,05$ maka hipotesis $\mathrm{H}_{1}$ diterima $\left(\mathrm{H}_{0}\right.$ ditolak $)$ dan dengan nilai adjusted $R$ Square 19,4\% serta sisanya $80,6 \%$ divariasi oleh faktor-faktor lain yang tidak diteliti peneliti.

4. Dari penelitian ini didapat bahwa variabel yang paling berpengaruh terhadap keputusan pembelian (Y) adalah variabel kualitas pelayanan $\left(\mathrm{X}_{2}\right)$ $t_{\text {hitung }} 2,963$ kemudian variabel saluran distribusi $\left(\mathrm{X}_{1}\right) \mathrm{t}_{\text {hitung }} 2,802$.

\section{Saran}

1. Pihak manajemen perusahaan sebaiknyalebih fokus lagi meningkatkan pada variabel kualitas pelayanan kepada pelanggan terutama dalam hal keandalan, kesigapan pelayanan dan kecepatan, dan kepastian pelayanan.

2. Pihak manajemen perusahaan harus selalu memelihara saluran distribusi dan kepuasan pelayanan kepada pelanggan.
3. Bagi Fakultas Ekonomi Universitas Prima Indonesia, hasil penelitian ini dapat menambah karya ilmiah di perpustakaan Universitas Prima Indonesia sehingga bermanfaat bagi mahasiswa-mahasiswi lainnya.

4. Bagi peneliti-peneliti berikutnya, hasil penelitian ini berguna bagi penelitian selanjutnya.

\section{DAFTAR PUSTAKA}

Abdullah, Thamrin dan Francis Tantri. 2012. Manajemen Pemasaran. Jakarta. Penerbit PT. Raja Grafindo Persada.

Adisaputro, Gunawan. 2014. Manajemen Pemasaran. Cetakan Kedua. Yogyakarta: UPP STIM YKPN.

Alma. Buchari 2011. Manajemen Pemasaran dan Pemasaran Jasa. Bandung : Penerbit Alfabeta.

Arikunto, Suharsimi. 2013. Prosedur Penelitian, Suatu Pendekatan Praktik. Jakarta : PT Rineka Cipta.

Ghozali, Imam. 2013. Aplikasi Analisis Multivariate dengan Program IBM SPSS 21. Cetakan Kelima. Jakarta: Penerbit Universitas Diponegoro.

Hariadi. 2013. Pengaruh Produk, Harga, Promosi dan Distribusi Terhadap Keputusan pembelian Konsumen pada Produk Projector Microvision. Jurnal Ilmu dan Riset Manajemen Volume 1 Nomor 1, Surabaya.

Haryono, Budi. 2016. How to win Customer Through Customer Service With Heart. Yogyakarta: CV. Andi Offset.

Hasan, Ali. 2013. Marketing dan Kasuskasus Pilihan. Penerbit CAPS, Yogyakarta.

Irawan. 2015. Pengaruh Produk, Harga, Promosi, Saluran Distribusi Terhadap Keputusan Pembelian 
Mobil Avanza. Jurnal Ilmu Riset dan Manajemen.

Kotler dan Keller. 2015. Marketing Management Edisi 1, Global Edition.

Laksana, Fajar. 2008. Manajemen Pemasaran Pendekatan Praktis. Cetakan Pertama. Yogyakarta: Graha Ilmu.

Lupiyoadi, Rambat. 2013. Manajemen Pemasaran Jasa. Ed.3, Penerbit Salemba Empat, Jakarta.

Machfoedz, Mahmud. 2007. Pengantar Pemasaran Modern. Penerbit UPP STIM YKPN.

Manap. Abdul. 2016. Revolusi Manajemen Pemasaran. Jakarta: Mitra Wacana Media.

Muhtadi dan Surahman. 2015. Pengaruh Kualitas Pelayanan dan Kepuasan Pelanggan terhadap Niat Beli Obat di Depo Farmasi Anggrek RSUP Dr. Hasan Sadikin, Bandung. Jurnal Farmasi Klinik Indonesia.

Nitisusastro, Mulyadi. 2013. Perilaku Konsumen Dalam Perspektif Kewirausahaan. Bandung: CV Alfabeta

Priyatno, Duwi, 2013. Mandiri Belajar Analisis Data Dengan SPSS, Cetakan I, Penerbit Gava Media, Yogyakarta.

Sanusi, Anwar. 2011. Metodologi Penelitian Bisnis. Cetakan Keempat, Jakarta: Salemba Empat.

Sangadji, E. M., \& Sopiah, 2013. Consumer Behavior: Perilaku Konsumen dan Strategi Pemasaran Jilid 2. Jakarta: Erlangga.

Schiffman, Leon dan Leslie Lazar Kanuk. 2007. Perilaku Konsumen. Jakarta. Penerbit Indeks.

Setiadi, Nugroho. 2015. Perilaku Konsumen. Cetakan Kelima, Jakarta: Kencana Prenada Media Group

Sunyoto, Danang. 2013. Dasar-dasar Manajemen Pemasaran Konsep, Strategi, dan Kasus. Yogyakarta, Penerbit CAPS.

Supranto, 2011. Pengukuran Tingkat Kepuasan Pelanggan untuk menaikkan Pangsa Pasar. Jakarta. Penerbit Rineka Cipta.

Swastha, Basu dan Hani Handoko, 2016. Manajemen Pemasaran Analisis Perilaku Konsumen. Yogyakarta. BPFE.

Tjiptono, dan Gregorious Chandra. 2012. Service Management. Ed. 2, Yogyakarta : CV Andi Offset.

Tjiptono, Fandy. 2015. Strategi Pemasaran, Cetakan Keempat. Yogyakarta: Andi Offset.

Zulganef. 2008. Metode Penelitian Sosial dan Bisnis. Cetakan Pertama. Yogyakarta: Graha Ilmu. 